Lecture Notes in Computer Science (including subseries Lecture Notes in Artificial Intelligence and Lecture Notes in Bioinformatics)Volume 10918 LNCS, 2018, Pages 673-6927th International Conference on Design, User Experience, and Usability, DUXU 2018 Held as Part of HCI International 2018; Las Vegas; United States; 15 July 2018 through 20 July 2018; Code 216309

\title{
A new software development model: Innovation through mobile application with UCD(Conference Paper)
}

- Espinoza, J.aEmail Author,

- Loarte, P.aEmail Author,

- Espinoza, C. ${ }^{\mathrm{b}}$ Email Author,

- Paz, F.aEmail Author,

- Arenas, J.aEmail Author

- View Correspondence (jump link)

- aPontificia Universidad Católica del Perú, Lima, 32, Peru

- bUniversidad Peruana de Ciencias Aplicadas, Lima 32, Peru

\begin{abstract}
View references (28)
Pursuit of innovation projects with the absent of a methodology to follow hampers the development of the software product as its complexity grows since the freedom of its own advancement is confused with the lack of order on it. Traditional and agile methodologies do not adapt to this kind of projects therefore, in this paper we aim to design a model that incorporates characteristics of both of them to get a solution of a need found in society. In this study, we focus on the construction of a mobile application that answer to the lack of a system that integrates pharmaceutical products from different establishment through the appliance of usability concept with the UCD (User centered design) approach. In this case we only detail about four of the seven stages proposed in the model developed with its techniques, tools and activities conducted. Results obtained show that the model proposed achieve the expectative and its use is not limited to just mobile applications but to any kind of software project. (C) 2018, Springer International Publishing AG, part of Springer Nature.
\end{abstract}

SciVal Topic Prominence

Topic: Design | Software engineering | agile methodologies Prominence percentile: 80.806

Author keywords

InnovationMobile applicationModelUsabilityUser-centered design

Indexed keywords 
Engineering controlled terms:

Engineering uncontrolled terms
Application programsMobile computingModelsProduct designUsability engin

Agile MethodologiesInnovation projectsMobile applicationsPharmaceutical $\mathrm{p}$ modelsSoftware productsSoftware projectUsability

Engineering main heading: Software design

- ISSN: 03029743

- ISBN: 978-331991796-2

- Source Type: Book series

- Original language: English

- DOI: 10.1007/978-3-319-91797-9_47

- Document Type: Conference Paper

- Volume Editors: Marcus A.,Wang W.

- Sponsors:

- Publisher: Springer Verlag 